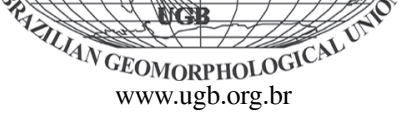

\title{
DINÂMICA GEOAMBIENTAL, PROCESSOS MORFODINÂMICOS E USO DAS TERRAS EM BREJO GRANDE, BAIXO SÃO FRANCISCO - SERGIPE
}

\author{
Neise Mare de Souza Alves \\ Departamento de Geografia/NPGEO - Universidade Federal de Sergipe (UFS) \\ Cidade Universitária Prof. José Aloíso de Campos, Bloco Departamental II - Jardim Rosa Elze. CEP: 49100-000 - Sao Cristovao, SE \\ neisemare@gmail.com
}

Aracy Losano Fontes

Departamento de Geografia/NPGEO - Universidade Federal de Sergipe (UFS) Cidade Universitária Prof. José Aloíso de Campos, Bloco Departamental II - Jardim Rosa Elze. CEP: 49100-000 - Sao Cristovao, SE aracyfontes@yahoo.com.br

Débora Barbosa da Silva

Departamento de Geografia/NPGEO - Universidade Federal de Sergipe (UFS) Cidade Universitária Prof. José Aloíso de Campos, Bloco Departamental II - Jardim Rosa Elze. CEP: 49100-000 - Sao Cristovao, SE deborabarbs@gmail.com

José Antônio Pacheco de Almeida

Departamento de Geografia/NPGEO - Universidade Federal de Sergipe (UFS)

Cidade Universitária Prof. José Aloíso de Campos, Bloco Departamental II - Jardim Rosa Elze. CEP: 49100-000 - Sao Cristovao, SE jalmeida@ufs.br

\begin{abstract}
Resumo
O presente trabalho apresenta o resultado da análise da dinâmica geoambiental em Brejo Grande, com ênfase nos processos morfodinâmicos e no uso e ocupação do solo. A área de estudo encontra-se em ambiente estuarino, sob clima úmido a semiúmido, com ocorrência de quatro meses secos, sujeita a processos de origem fluvial, oceanográfica, eólica e intervenções antrópicas. A ação e a intensidade dos processos se repercutem na paisagem e influenciam as formas de uso das terras. Na análise aplicaram-se os pressupostos sistêmicos da Ecodinâmica (Tricart, 1977) e dos Geossistemas (Bertrand, 1971). O estudo requereu a interpretação de aerofotos e ortofotocartas (Sergipe, 2003) e, observações de campo para compreensão da organização da paisagem, das características dos processos e entrevistas com moradores. Com as informações foram confeccionados dois mapas, um de uso das terras e outro morfodinâmico, com aplicação de geotecnologias, utilizando-se técnicas de sensoriamento remoto e geoprocessamento. Os resultados indicam que as características da hidrodinâmica do rio São Francisco se repercutem nos processos morfodinâmicos atuantes nas unidades que compõem a Planície Costeiro-Deltaica Quaternária e, nas formas de exploração econômica das terras. No setor norte encontra-se um conjunto de pequenos canais onde se observa formas de controle antrópico sobre a drenagem com propósitos econômicos - a irrigação para a rizicultura. Por sua vez, no setor sul e entorno do rio Parapuca, estão sendo instalados viveiros para a carcinicultura e piscicultura, enquanto o cultivo do coco da baía encontra-se disseminado nas áreas de solos arenosos.
\end{abstract}

Palavras-chave: processos morfodinâmicos; uso da terra; rio São Francisco. 


\begin{abstract}
The present paper shows dynamics environmental analysis in Brejo Grande county Sergipe state Brazil, with emphasis on morphodynamics processes and landuse. The study area is located on a estuary environment, from humid to semi humid climate, with four dry months. The lancscape reflect the oceanographical, aeolian and fluvial process and human interventions. The analysis is based on ecodynamics theory (Tricart, 1977) and geossystem theory (Bertrand, 1971). The identification of landscape arranjement was made from aerial photographs interpretations and inhabitant's interview. From the technology based on remote sensing and geographical information system were made a landuse and morphodynamics maps. The results indicate that the characteristics of the hydrodynamics of the São Francisco river has influence on morphodynamics processes, the geomorphological units that compounds the Delta and Coastal Plain Quaternary and the caracteristc of economical exploration in the landscape. In the north portion there is a set of small canals made for rice culture irrigation. In the south portion and surroundings of the Parapuca river, are being constructed fisheries for the culture of fishes and shrimps, as well there is coconut culture exploration spreading in the sandy areas.
\end{abstract}

Keywords: morphodynamics processes, use of lands, São Francisco river.

\section{Introdução}

Os estudos que objetivam conhecer a dinâmica geoambiental de determinada área constituem uma iniciativa essencial para a sustentabilidade dos recursos naturais e manutenção das comunidades locais.

Os sistemas ambientais que conjugam a dinâmica fluvial de grandes bacias hidrográficas com a dinâmica costeira apresentam-se como distintos em relação aos demais, pois associam elementos e processos dinâmicos de diferentes origens que interagem simultaneamente e se repercutem no espaço geográfico.

Esta situação representa as condições básicas da dinâmica geoambiental no município de Brejo Grande, onde determinadas áreas da paisagem apresentam sinais indicativos de intensificação da morfogênese, resultantes da interação dos condicionantes naturais e antrópicos atuantes no baixo curso da bacia do rio São Francisco. Considerando os pressupostos da concepção sistêmica, esta interação se repercute não apenas nos componentes biofísicos da paisagem, mas também na estrutura e organização da vida socioeconômica da população local.

O presente estudo apresenta uma análise geoambiental da área de Brejo Grande com base na aplicação dos princípios sistêmicos, tomando por base a Ecodinâmica (Tricart, 1977) associada aos Geossistemas (Bertrand, 1972) com o objetivo de analisar o quadro em que se processa a morfodinâmica no município e suas repercussões no atual modelo de exploração econômica do espaço.

\section{Caracterização Geoambiental e Socioeconômica da Área}

A área de estudo compõe o território do Baixo São Francisco Sergipano (SEPLAN, 2007). Brejo Grande está localizado à margem direita, no baixo curso do rio São Francisco, integrando o sistema estuarino-lagunar do referido rio (Carvalho \& Fontes, 2006). O município possui uma área de $149,2 \mathrm{~km}^{2}$ e, dista aproximadamente $137 \mathrm{~km}$ da capital sergipana, tendo a sede como coordenadas geográficas $10^{\circ} 25^{\prime} 28^{\prime \prime}$ de latitude Sul e $36^{\circ} 07^{\prime} 44^{\prime \prime}$ de longitude Oeste (Bonfim, 2002). Limita-se ao norte com o estado de Alagoas; a noroeste com o município de Ilha das Flores; a leste com o rio São Francisco, a oeste e sudoeste com o município de Pacatuba e, ao sul com o oceano Atlântico.

A área encontra-se submetida a um contexto climático regional úmido a semi-úmido, caracterizado por temperatura média anual elevada durante o ano todo e pluviosidade apresentando variabilidade na distribuição anual, com período chuvoso de abril a julho e ocorrência de quatro a cinco meses secos durante a estação primavera-verão. Assim, o clima destaca-se como um importante elemento condicionante da dinâmica ambiental. Os totais anuais de chuva variam de 1200 a $1500 \mathrm{~mm}$ (UFS, 1979).

No município a vegetação está representada por espécies pertencentes às Formações Pioneiras, apresentando recursos florísticos com espécies típicas, características dos ambientes de Áreas de Influência Marinha (Restinga), de Influência Fluviomarinha (Mangue) e de Influência Fluvial (Formações Pioneiras Arbustivas das Áreas de Inundação e das Áreas de Acumulação Eólica). Esta vegetação se encontra em ambientes de sedimentação recente, sobre solos com baixa fertilidade, uma vez que "[...] o material de contribuição (fluvial, marinho, fluviomarinho, eólico, etc.) não teve tempo de se edafizar" (BRASIL, 1983, p. 609).

Segundo Silva (2007) na área de estudo encontram-se as seguintes classes de solos: Espodossolo Ferrihumilúvico; Gleissolo Háplico; Neossolo Quartzarênico e solos 
indiscriminados de mangue. Estas classes dominantes se distribuem na paisagem em função de certas características do modelado e de sua organização, apresentando-se quase sempre em associações com outras classes de solos.

Verificou-se que os Espodossolos apresentam textura predominantemente arenosa. Estes solos possuem baixa fertilidade e são encontrados em ambientes de umidade elevada, áreas abaciadas, depressões ou locais onde haja elevação ou afloramento do lençol freático e ocorrência de vegetação de restinga.

Os Gleissolos estão presentes na planície de inundação do rio São Francisco. São encontrados em áreas de saturação hídrica cujas condições favoreçam a existência de um horizonte de subsuperfície com gleização expressiva, sob outro onde predomina a fração areia. Estes solos podem ocorrer em associações com os Neossolos Flúvicos, que se desenvolvem a partir dos sedimentos fluviais depositados nas margens, estando organizados em camadas estratificadas sem relação pedogenética entre si. A textura indiscriminada que os caracteriza indica a heterogeneidade das frações granulométricas.

Os Neossolos Quartzarênicos são constituídos por elevados percentuais das frações areia grossa e areia fina. Nesta classe de solo predomina a textura areia franca e areia até uma profundidade mínima de $150 \mathrm{~cm}$. Na área de estudo, estes solos são oriundos de depósitos marinhos, de baixa fertilidade química e, as características do material de origem concorrem para reduzir a atuação dos processos pedogenéticos. A textura arenosa favorece a infiltração e a baixa retenção de umidade, tornando-os susceptíveis ao escoamento subsuperficial e/ou a ação dos ventos.

Os Solos Indiscriminados de Mangue são solos originados de depósitos fluviomarinhos, constituídos por matéria mineral e orgânica. De modo geral, predomina textura fina em virtude do material de origem. Estão em ambiente anaeróbico, ácido, com salinidade elevada por influência das águas marinhas e sobre eles se encontra o ecossistema manguezal.

A geologia está representada por Formações Superficiais do Quaternário (Santos et al., 1998). Na área tais depósitos correspondem às Coberturas Holocênicas, assim representadas: no segmento centro- norte da área são encontrados os Depósitos flúvio-lagunares, constituídos por areia e silte argilosos ricos em matéria orgânica e, nas margens do rio São Francisco estes depósitos são tipicamente fluviais; no segmento centro-sul, área do entorno do canal e rio Parapuca sob a influência das marés, são encontrados os Depósitos de pântanos e mangues, constituídos por sedimentos argilo-siltosos ricos em matéria orgânica. Entre os dois segmentos referidos são encontrados os Depósitos eólicos litorâneos, representados por um conjunto mais antigo de dunas parabólicas fixadas pela vegetação, que se desenvolveu sobre os terraços marinhos holocênicos,. Estes depósitos são compostos de areias bem selecionadas com grãos arredondados. Na foz do rio São Francisco e no ambiente praial são encontrados os Terraços marinhos, representados por depósitos de areias litorâneas bem selecionadas, com conchas marinhas e tubos fósseis de Callianassa.

A evolução geomorfológica da área de estudo foi conduzida por uma combinação de eventos tectônicos, natureza das litologias, mudanças climáticas do Quaternário e oscilações no nível do mar. Em condições naturais, a evolução geomorfológica atual teria uma dinâmica conduzida por processos onde a água seria o agente principal. Entretanto, a análise da situação atual identifica também o homem como um importante fator morfogenético, pois suas ações interferem na dinâmica da paisagem.

Considerando o exposto, na área de estudo identificouse uma macrounidade geomorfológica, a Planície Costeirodeltaica Quaternária do rio São Francisco, caracterizada por sedimentos fluviais influenciados pelo ambiente costeiro. Devido a tais condições, ela se apresenta integralizada a partir das relações dinâmicas estabelecidas entre unidades geomorfológicas menores. Estas unidades são: a Planície Fluviolagunar, a Planície Fluviomarinha e a Planície Litorânea.

A primeira unidade apresenta-se plana com áreas deprimidas, estando sujeita à inundação em razão da subida do lençol freático pela proximidade do nível de base local. Verifica-se forte controle antrópico da drenagem com o objetivo de assegurar as condições de exploração econômica das terras com a rizicultura.

A segunda unidade encontra-se configurada por um conjunto de ilhas que preservam no seu interior "antigos pontais arenosos imobilizados pela progradação" (Dominguez et al., 1983, p. 100) que constituem indicadores geomórficos do sentido preferencial da deriva litorânea dos sedimentos arenosos e, uma área de cordões litorâneos holocênicos onde se encontram dunas fixadas pela vegetação associadas a baixadas interdunares, com afloramento do lençol freático.

A unidade Planície Litorânea engloba os terraços marinhos holocênicos e o ambiente praial. Nesta unidade os agentes atmosféricos, marinhos e eólicos respondem por uma dinâmica intensa sobre as morfologias e ambientes.

É marcante a presença de diques marginais construídos ao longo do canal do rio São Francisco para evitar a erosão. Parte deles encontra-se protegida com mantas fabricadas com borracha de pneus e sacos de areia, dispostos em alguns setores para evitar o solapamento das margens. A foz exibe uma feição deltaica com o alinhamento de cordões litorâneos, indicativos de posicionamentos pretéritos da linha de costa, reflexo das condições ambientais do Quaternário.

No que se refere aos recursos hídricos, Brejo Grande está à margem direita do rio São Francisco, um rio perene, 
vital para o desenvolvimento econômico nacional e regional e, que tem papel fundamental na geração de energia. Por conta disso, encontram-se instaladas inúmeras barragens no seu curso a fim de assegurar a realização de projetos de desenvolvimento de interesse público e privado, tanto para a geração de energia quanto para a irrigação. Tais projetos quase sempre minimizam as repercussões que estas intervenções podem provocar na dinâmica do sistema geoambiental e na organização social e econômica. A foz e a planície costeira do rio São Francisco têm sido alvo de estudos que buscam explicar a dinâmica atuante (Bittencourt et al., 1983; Dominguez et al., 1983; Barbosa, 1997; Fontes, 2003; Medeiros, 2003; Barbosa \& Dominguez, 2004; Bittencourt et al., 2007).

Os recursos hídricos da área de estudo abrangem também uma rede de pequenos riachos, quase todos tributários de duas drenagens, o rio Paraúna e o rio Parapuca. De modo geral, apresentam-se meandrantes em razão da proximidade do nível de base local. As lagoas que ocorrem na área entremeiam-se nas baixadas em contato com as dunas inativas.

A grande disponibilidade hídrica na área contribui para que as formas de exploração das terras sejam definidas em função das características das feições morfológicas e das formações superficiais. Além disso, as precárias condições de infra-estrutura obrigam parte da população a utilizar as águas disponíveis para uso doméstico, inclusive as do rio São Francisco.

O passado econômico revela o município de Brejo Grande como uma antiga e importante área de cultivo de canade-açúcar. Com o passar do tempo, a cana-de-açúcar cedeu lugar aos cultivos do algodão, do arroz e do coco-da-baía. Na década de 50, o município apresentava uma grande produção de sal marinho, nas ilhas próximas ao canal do Parapuca, onde a salinidade das águas é maior.

Nos dias atuais Brejo Grande é reconhecido como um grande produtor de arroz. Sua economia é dinamizada pela exploração do petróleo, encontrando-se implantada na área uma estação coletora da Petrobrás.

Segundo dados do censo demográfico do IBGE (2004) a população brejograndense corresponde a um total de 7.102 habitantes, dos quais 55\% residindo na zona urbana. Embora se verifique esta concentração, a população urbana mantém uma intensa relação com o espaço rural. Os dados revelam ainda que dos 1.613 domicílios cadastrados, cerca de 1/3 não possuíam abastecimento de água tratada, coleta de lixo e instalações sanitárias. Estas condições revelam o baixo padrão de qualidade de vida da população e a exposição do ambiente à degradação.

Como ocorre nas comunidades ribeirinhas, a atividade pesqueira é praticada por grande parte da população, principalmente, a pesca artesanal e a captura do caranguejo.
Estas atividades têm um forte significado social para a comunidade, pois garantem a sobrevivência de muitas famílias. Atualmente, muitos dizem enfrentar dificuldades em razão da diminuição do pescado e apontam entre as principais causas: a implantação das barragens no curso do rio São Francisco, especialmente a partir do funcionamento da Usina Hidrelétrica de Xingó e, da instalação de viveiros para carcinicultura.

\section{Materiais e Métodos}

Para proceder a realização do estudo proposto, foram utilizados os seguintes materiais e procedimentos metodológicos: pesquisa bibliográfica; levantamento e análise dos documentos cartográficos; trabalhos em campo e, confecção de mapas.

A pesquisa bibliográfica foi realizada junto aos órgãos públicos do estado de Sergipe (SEPLAN, ADEMA, CODISE), além da coleta de materiais disponíveis nos acervos virtuais de instituições e bibliotecas de Universidades.

Foram consultados e analisados os seguintes produtos cartográficos: os mapas planialtimétricos na escala de 1:100.000, folhas Japaratuba (SC.24-Z-B-V), Cabeço (SC.24Z-B-VI), Piaçabuçu (SC.24-Z-B-III) da Superintendência do Desenvolvimento do Nordeste (SUDENE,1974 a, b, c); e folha Propriá (SC.24-Z-B-II) da Diretoria do Serviço Geográfico do Ministério do Exército (Brasil,1971); os mapas temáticos do Projeto RADAMBRASIL (Brasil, ,1983), escala 1:1.000.000; os mapas do Atlas de Sergipe, escala 1:500.000 (UFS, 1979); o mapa e texto do Mapa Geológico do Estado de Sergipe, escala 1:250.000 (Santos et al., 1998); o Mapa de Uso da Terra do Estado de Sergipe, escala 1:350.000 (IBGE, 1995); o Mapa Exploratório - Reconhecimento de Solos do Estado de Sergipe, escala 1:500.000 (Silva, 2007).

Além disso, foi realizada a fotointerpretação da área através da estereoscopia, utilizando-se 34 fotografias aéreas coloridas, na escala 1:25.000, obtidas junto à Secretaria do Planejamento e da Ciência e Tecnologia do estado de Sergipe; e a interpretação de 12 ortofotocartas, através de meio digital, na escala 1:10.000.

Para a confecção do mapa de uso e ocupação do solo e, do mapa morfodinâmico/geossistêmico foram utilizadas as ortofotocartas supracitadas, já georreferenciadas pelo órgão cedente no formato imagem com extensão GEOTIFF. Sua articulação se deu a partir do processo de mosaico, utilizandose o programa SPRING 4.3.3. Em seguida com o uso do programa ARCVIEW 3.2, foram geradas classes e pontos para representar os diferentes tipos de uso e ocupação do solo sendo o mesmo efetuado para as unidades geossistêmicas e processos dinâmicos.

O polígono referente ao limite do município (no formato shape) foi obtido no banco de dados do Atlas Digital Sobre Recursos Hídricos de Sergipe (SEPLANTEC, 2002). Estes 
Dinâmica geoambiental, processos morfodinâmicos e uso das terras...

elementos foram projetados e adicionados a uma camada para a visualização do mosaico - ortofotos e limites do município - a fim de promover o recorte das informações referentes à área de estudo. Em seguida foram definidas as classes de cada tipo de uso e ocupação do solo, as unidades geossistêmicas e processos dinâmicos atuantes, salvos com nomes específicos. Então se procedeu à digitalização dos temas criados na interpretação das fotografias aéreas e ortofotos. As referidas classes e pontos gerados foram salvos no formato shape. Ao final da digitalização utilizou-se o programa ARCGIS 9.0-ARCMAP, passando-se à confecção dos mapas, projetando-os num layout.

As campanhas de campo permitiram a aplicação de técnicas de observação para as características da organização da paisagem, da dinâmica dos processos atuantes e, da estrutura socioeconômica. Além disso, possibilitou entrevistas com lideranças locais objetivando ampliar as informações e conhecer detalhes para reconstituir o quadro ambiental e socioeconômico da área num passado recente.
Foram realizadas três viagens a campo, orientadas por um mapa geomorfológico preliminar, totalizando onze dias. Aproximadamente, vinte horas foram utilizadas para percorrer de barco os pequenos canais de drenagem, as ilhas e o setor da foz do rio São Francisco.

\section{4 - Resultados e Discussões}

Considerando-se as análises procedidas e a aplicação das taxonomias de Bertrand (1971) e Tricart (1977), a área de estudo corresponde a Região Natural em Mosaico da Planície Costeiro-deltaica Quaternária, integrada por três unidades geossistêmicas com características diferenciadas em relação à evolução geomorfológica, à ação dos processos morfogenéticos atuantes e ao tipo de exploração econômica do solo (Figura 1). Dessa forma identificaram-se os seguintes Geossistemas (Figura 2): I- Geossistema em Resistasia Antrópica da Planície Fluviolagunar; II- Geossistema em Resistasia Natural da Planície Litorânea; III- Geossistema em



Figura 1 - Mapa de exploração econômica do solo do município de Brejo Grande. 


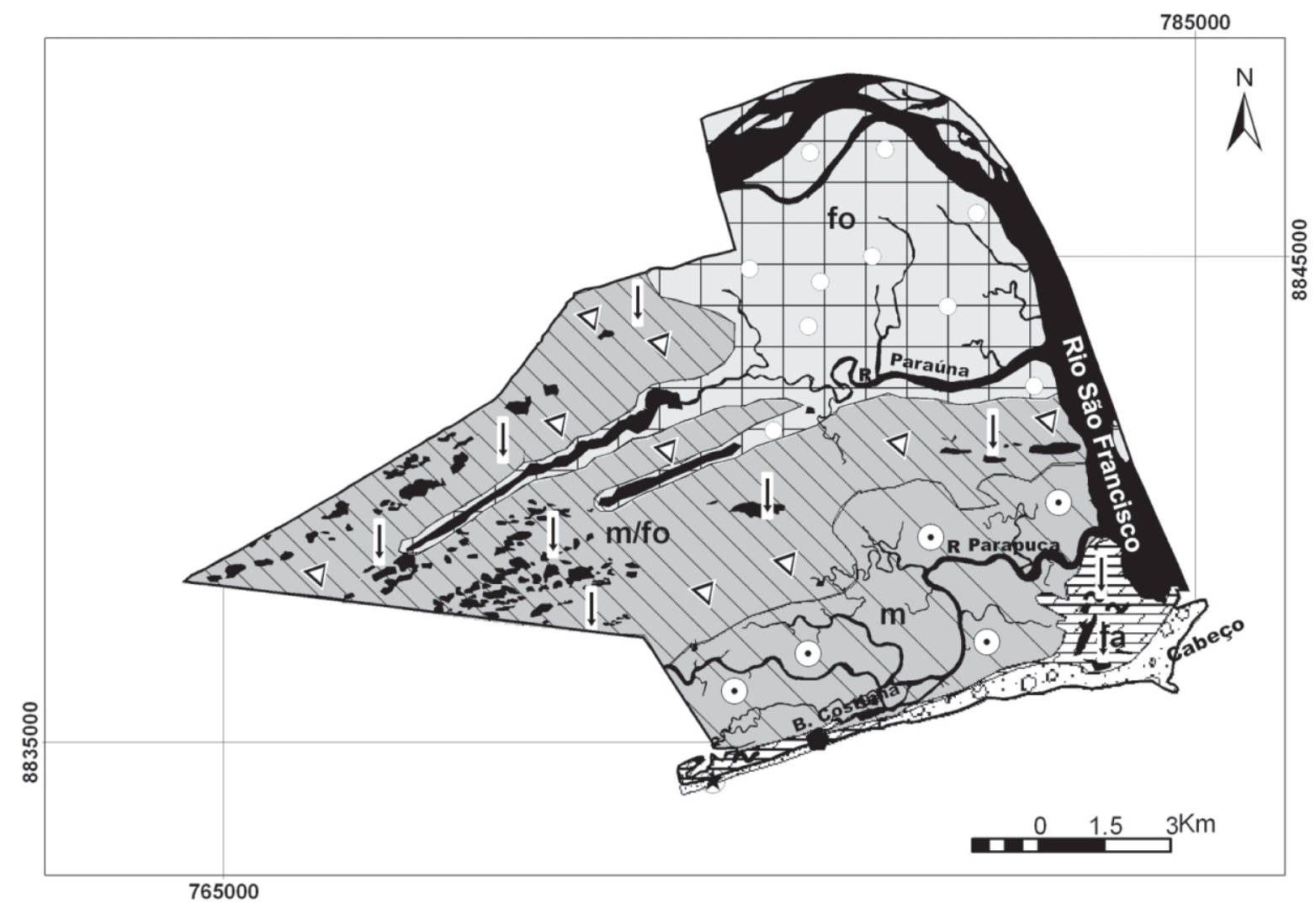

\section{GEOMORFOLOGIA}

I - PLANÍCIE COSTEIRO-DELTAICA QUATERNÁRIA

$\square$ I.I - Planície Fluviolagunar
$\square$ I.II - Planície Fluviomarinha
$\square$ I.III - Planície Litorânea

PROCESSO DINÂMICO DOMINANTE

I - ACUMULAÇÃO

0 FLUVIAL - Planicie de inundação

- FLUVIOMARINHA - Área de mangue

$\checkmark$ EÓLICA - Dunas e baixadas interdunares

II - ESCOAMENTO

5 SUPERFICIAL - Fluvial

1 SUBSUPERFICIAL - Infiltração

\section{III - EROSÄO E ACUMULAÇÃO}

$\sim$ MARINHA - Terraços litorâneos e praia

$\therefore: C$ Área erodida por processos costeiros

Área acrescida por processos costeiros
COMPARTIMENTAÇÃO GEOSSISTÊMICA

H I - Geossistema em Resistasia Antrópica da Planície Fluviolagunar

II - Geossistema em Resistasia Natural da Planície Litorânea

III - Geossistema em Mosaico da Planície Fluviomarinha

NIV III.I - Geofácies em Resistasia Antrópica dos Cordões de Dunas e Baixadas Interdunares

$\triangle$ III.II - Geofácies em Biostasia Precária do Manguezal

GRAU DE ANTROPIZAÇÃO

$\begin{array}{ll}\text { fo } & \text { Forte } \\ \mathrm{m} / \mathrm{fo} & \text { Médio à forte } \\ \mathrm{m} & \text { Médio } \\ \mathrm{fa} & \text { Fraco }\end{array}$

$\longrightarrow$ Limite de Brejo Grande

Figura 1 - Mapa de Geossistemas do município de Brejo Grande. 
Dinâmica geoambiental, processos morfodinâmicos e uso das terras...

Mosaico da Planície Fluviomarinha composto por duas subunidades: a Geofácies em Resistasia Antrópica dos Cordões de Dunas e Baixadas Interdunares e a Geofácies em Biostasia Precária do Manguezal.

O Geossistema em Resistasia Antrópica da Planície Fluviolagunar abrange a planície de inundação do rio São Francisco, no setor norte da área de estudo, onde se observa a presença de atividades extrativas do campo petrolífero e a rizicultura (Figura 1). Os cultivos se desenvolvem sobre os Gleissolos, solos de maior fertilidade da área, encontrados nos ambientes de saturação hídrica permanente e/ou temporária, condições propícias ao desenvolvimento da rizicultura. Estão presentes também alguns cultivos de subsistência.

Constata-se, intensa exploração econômica e o uso de mecanismos de controle antrópico para a drenagem, com a construção de "muros" - denominação local para os diques

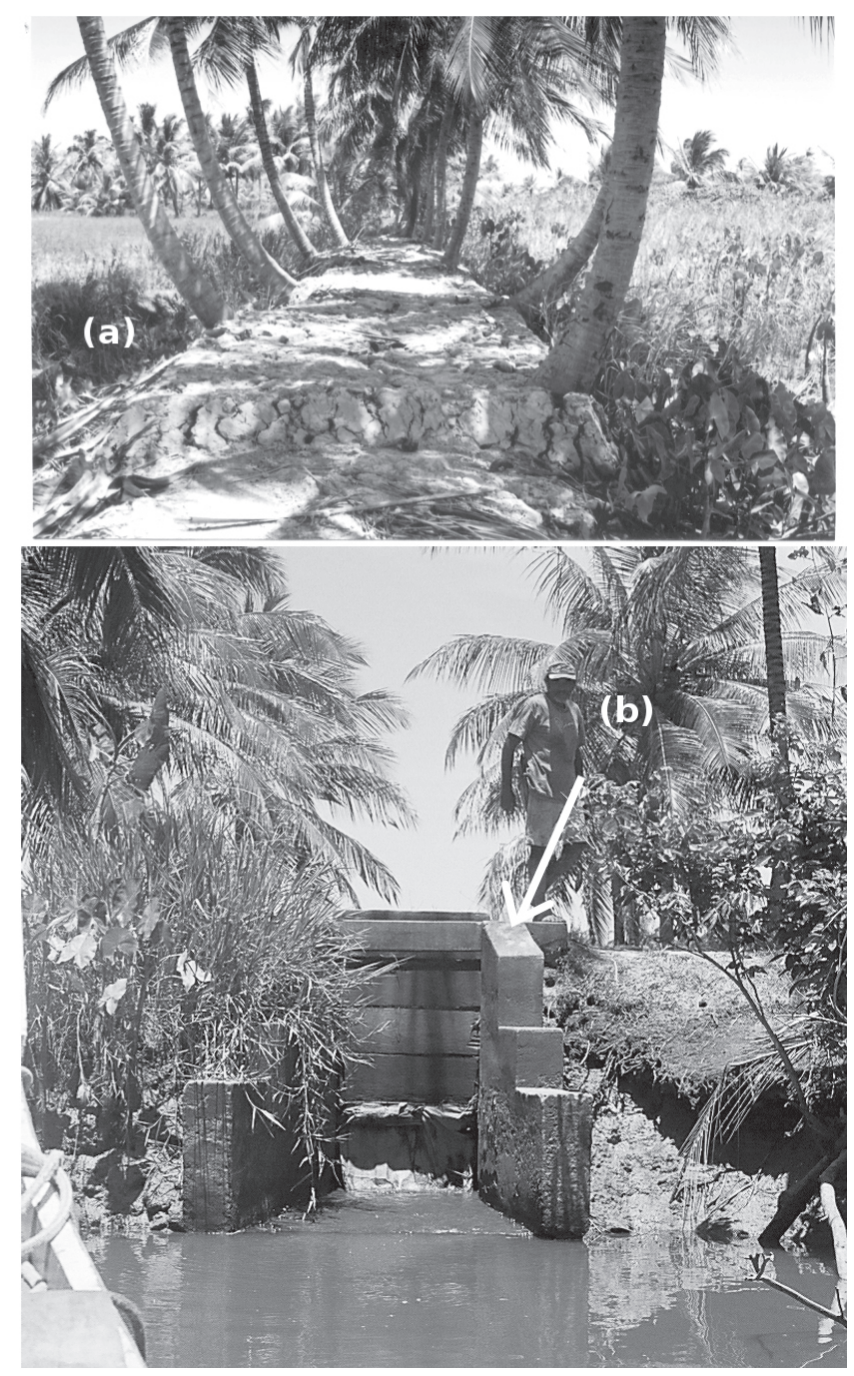

Figura 3-(a) "Muro" coberto por coqueiros e, (b) "porta d'água" utilizada para controlar a irrigação em área de rizicultura.

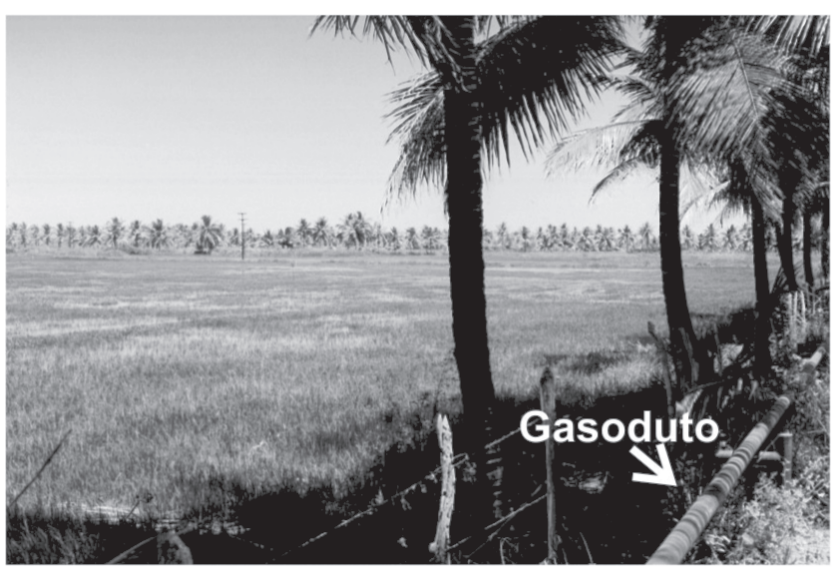

Figura 4 - Área de cultivo do arroz e tubulação de gasoduto em superficie.

que barram e orientam o escoamento das águas dos pequenos canais através das "portas d'águas"- para a irrigação do arroz; ocorre também a prática da queimada no preparo do terreno para o plantio e o uso de tratores (Figura 3).

Estas intervenções desorganizam a drenagem, que apresenta um padrão falsamente retangular; reduzem a velocidade do escoamento fluvial, favorecendo os processos de acumulação dos materiais finos nas baixadas; o assoreamento dos rios; além de alterações nas características físicas e químicas dos solos.

Neste Geossistema se verifica a maior concentração de população. Entretanto, constitui uma unidade com fraca predisposição à instabilidade em função da topografia, embora potencialmente haja riscos ambientais, por conta da existência de gasoduto que corta a área com trechos subterrâneos e em superfície conduzindo substância tóxica e inflamável (Figura 4). A contaminação do meio ambiente pode ocorrer a partir de vazamentos devido a corrosão ou ruptura dos dutos e problemas na soldagem das tubulações, entre outros. Considerando o estado morfodinâmico este Geossistema corresponde aos Meios Relativamente Instáveis.

O Geossistema em Resistasia Natural da Planície Litorânea corresponde a uma área com baixo nível de ocupação humana e fraco grau de antropização. Ela abrange a área de ocorrência dos terraços marinhos holocênicos e o ambiente praial (Figura 5).

A intensidade da morfogênese nesta unidade é definida pela ação conjugada processos costeiros atuantes - ventos, ondas, oscilações das marés e correntes marinhas - que têm sua ação favorecida e intensificada por intervenções humanas presentes na área continental da bacia do rio São Francisco e, que se repercutem a jusante (Figura 6).

A dinâmica no ambiente estuarino do rio São Francisco tem proporcionado mudanças nas morfologias da desembocadura e em setores das margens, no decorrer do tempo. 


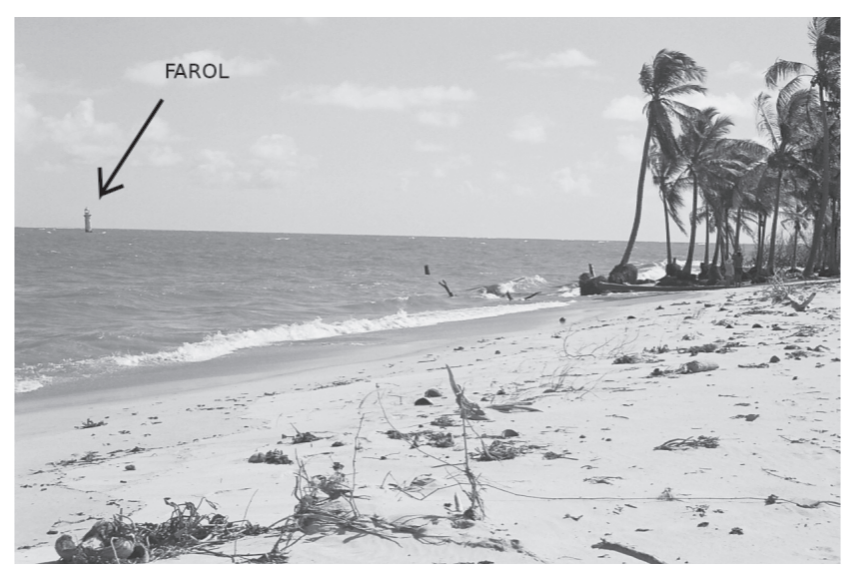

Figura 5 - Erosão da praia do Cabeço resultante da ação dos processos dinâmicos costeiros na Planície Litorânea - foz do rio São Francisco.

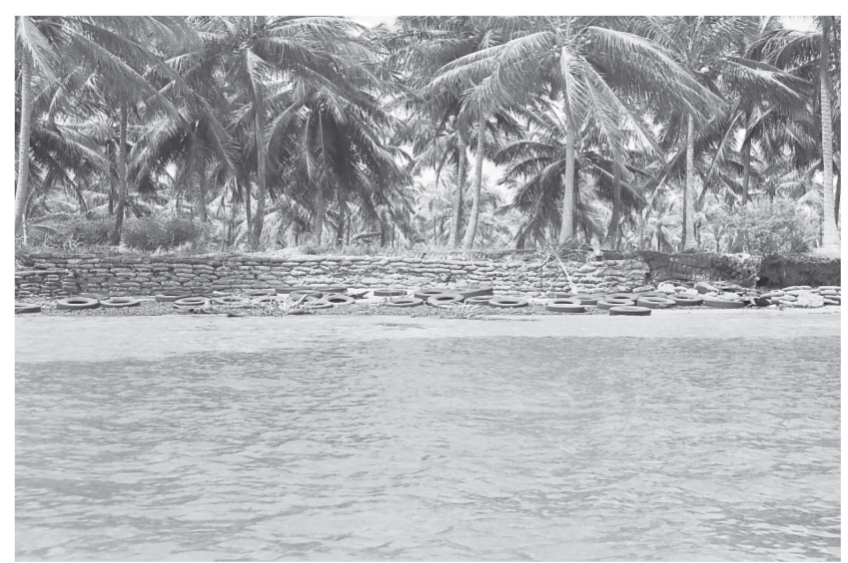

Figura 6 - Sacos de areia e mantas de pneus como estratégia para a contenção da erosão nas margens do rio São Francisco.

Almeida \& Gomes (2006) constataram estas alterações na paisagem da foz do rio através de análise comparativa temporal efetuada com o uso de imagens de satélite para os períodos de 1986, 2001 e 2005. Neste estudo foram registradas áreas de perdas e ganhos de território na foz do São Francisco.

Os mapas de uso e ocupação do solo (Figura 1) e o mapa morfodinâmico e geossistêmico (Figura 2) registram as áreas de acréscimo e de erosão que foram identificadas a partir da comparação dos limites originais da área (SEPLANTEC, 2002) com as fotografias aéreas de 2003.

Esta dinâmica na foz do rio São Francisco teve como conseqüência mais grave a destruição do povoado do Cabeço (Figura 7).

Além disso, a população aponta também o desaparecimento da antiga área da comunidade da Barra da Costinha, na praia do Arambipe. A dinâmica costeira fechou a área da antiga barra, deslocando-a para sudeste, proporcionando a destruição de casas, de plantações de coqueiros, além do esprai-

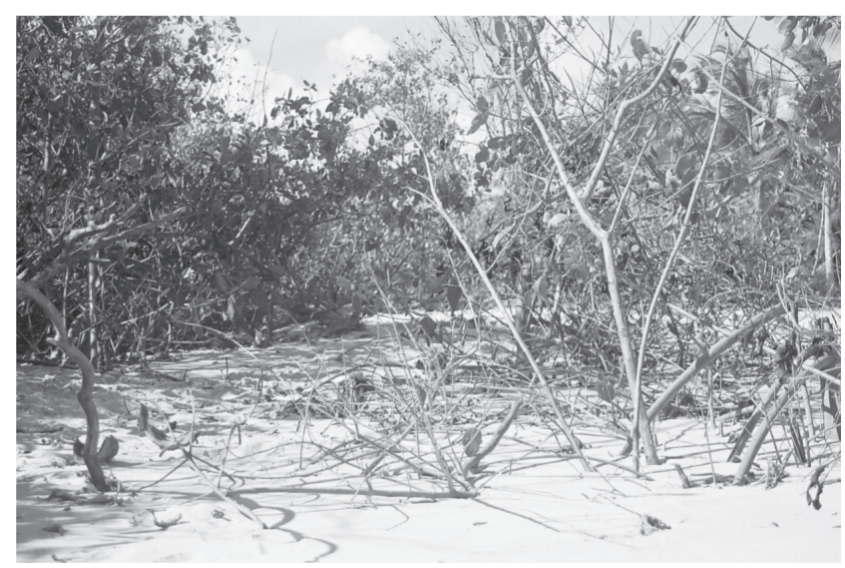

Figura 7 - Morte do manguezal por aterro decorrente da ação dos processos oceanográficos - Praia do Cabeço.

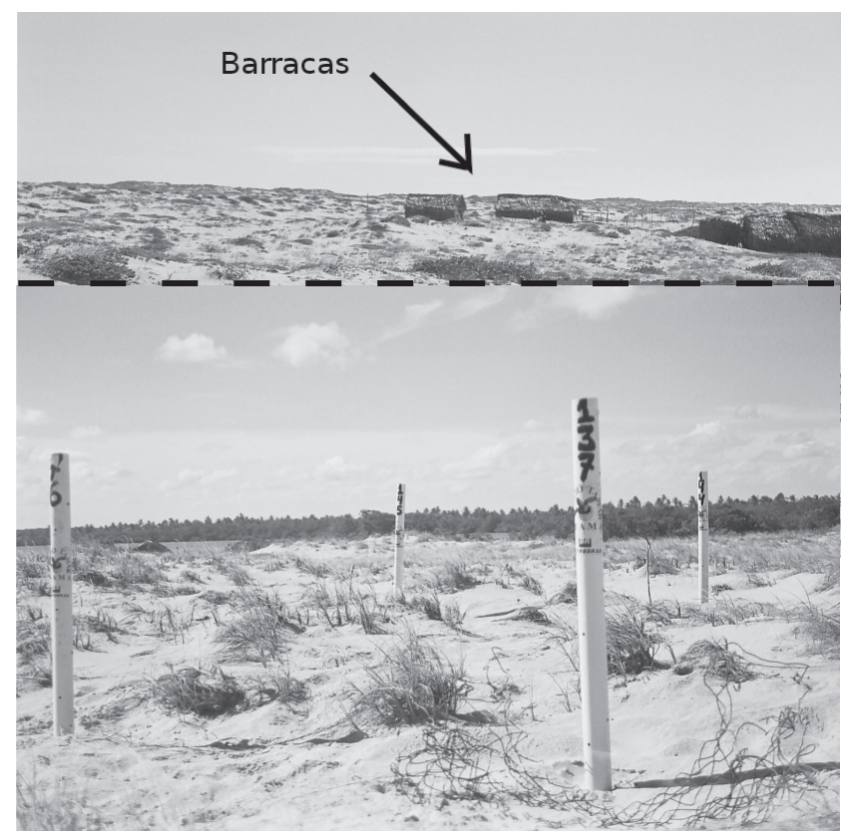

Figura 8-Área de desova de tartarugas marinhas (Projeto Tamar) e barracas de praia - Boca do Arrombado.

amento das areias do campo de dunas local. Nas proximidades dessa área são encontradas algumas barracas para dar apoio aos freqüentadores da praia e, uma área de desova de tartarugas marinhas do Projeto TAMAR, na localidade Boca do Arrombado (Figura 8).

Os terraços marinhos localizados próximos à foz apresentam atualmente pequenas áreas com plantio do coco-dabaía em meio à vegetação de restinga (Figura 1).

Considerando o exposto, o Geossistema em Resistasia Natural da Planície Litorânea se apresenta como uma área de elevada instabilidade por fatores naturais dinâmicos, atuantes no ambiente costeiro. Apesar disso, hoje se reconhece que as intervenções ocorridas no interior de uma bacia 
hidrográfica costumam se repercutir na sua foz e adjacências. Dessa forma, esta unidade pode ser associada aos Meios Fortemente Instáveis.

Segundo Motti \& Motti (1973, p. 386) os geossistemas "não são necessariamente muito homogêneos e podem associar setores em vários estados de evolução, que são os Geofácies [...]."

Assim, a terceira unidade geossistêmica apresenta-se composta por duas Geofácies com características distintas na sua morfodinâmica e composição sedimentológica. O Geossistema em Mosaico da Planície Fluviomarinha engloba a Geofácies em Resistasia Antrópica dos Cordões de Dunas e Baixadas Interdunares e a Geofácies em Biostasia Precária do Manguezal.

A primeira Geofácies está composta por campos de dunas holocênicas fixadas pela vegetação. Em suas bases se evidenciam baixadas onde se formam lagoas por afloramento do lençol freático, que são mantidas pelo escoamento subsuperficial e pela infiltração, em razão da permeabilidade das formações superficiais, essencialmente arenosas.

Os Neossolos Quartzarênicos, arenosos e de baixa fertilidade química, favorecem o cultivo do coco. Nas lagoas, principalmente, naquelas de caráter permanente e associadas aos pequenos canais de drenagem, são construídos barramentos para permitir a exploração econômica com a implantação das atividades da aqüicultura (viveiros para a criação de camarões e/ou peixes). Assim, esta Geofácies encontra-se submetida a mudanças na ação e intensidade dos processos.

A implantação dos cultivos expõe os solos arenosos à ação dos ventos podendo reativar o processo de deflação eólica na área das dunas. Por sua vez, os barramentos das lagoas contribuem para o assoreamento dos pequenos canais e colmatação de áreas deprimidas, além de propiciar riscos de contaminação do lençol devido ao uso das substâncias químicas necessárias ao preparo e à manutenção dos viveiros.

Nesta Geofácies em Resistasia Antrópica dos Cordões de Dunas e Baixadas Interdunares o desmatamento de parte da vegetação de restinga, tanto para fins agrícolas como para uso doméstico, permite identificar apenas algumas manchas remanescentes da vegetação original (Figura 1).

O grau de antropização é médio a forte (Figura 2). Esta Geofácies apresenta elevado potencial morfodinâmico em razão do tipo de sedimento e das formas atuais de uso e ocupação do solo que podem propiciar condições para a reativação dos processos eólicos. Tal análise, do ponto de vista da morfodinâmica, permite relacionar esta Geofácies aos Meios Instáveis.

A Geofácies em Biostasia Precária do Manguezal corresponde a uma planície inundação resultante de proces- sos de acumulação de sedimentos fluviais e marinhos, cortada pelo rio Parapuca e pequenos canais de maré, que está sob a influência permanente das águas oceânicas.

Nestas condições, por conta da presença de salinidade, os solos apresentam restritivo uso agrícola, observando-se na área o domínio das atividades extrativas animal - pesca artesanal e captura de crustáceos, principalmente, do caranguejo - e vegetal, corte das árvores para uso doméstico, como lenha (Figuras 9 e 10).

Atualmente, áreas do mangue estão sendo desmatadas para dar lugar a implantação dos viveiros de carcinicultura e piscicultura e, a expansão das atividades salineiras. Sendo o manguezal um ecossistema sensível e fundamental na proteção das zonas costeiras, estas interferências podem contribuir para romper o precário equilíbrio e desencadear processos que alterem a dinâmica do sistema costeiro.

Dessa forma, esta Geofácies constitui um ambiente vulnerável e potencialmente sujeito à instabilidade, podendo ser identificada com os Meios Relativamente Estáveis

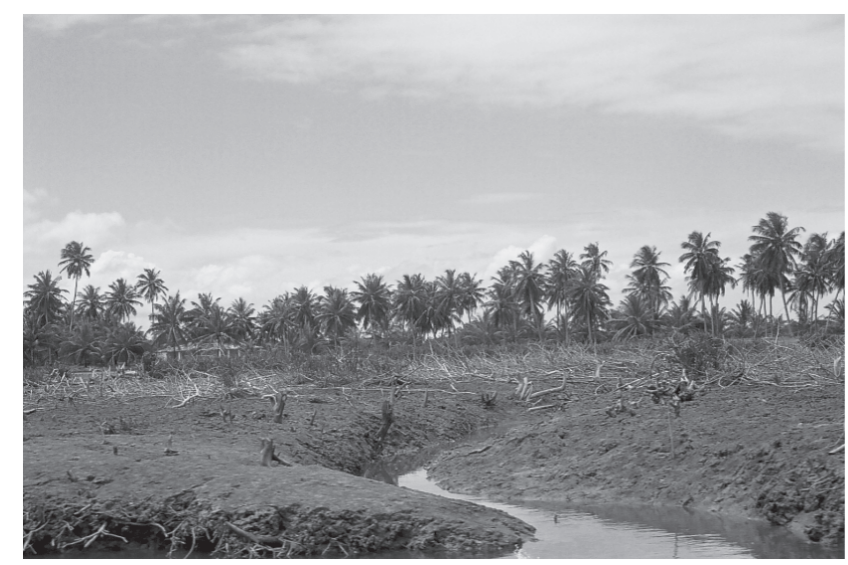

Figura 9 - Corte de mangue para implantação de viveiros.

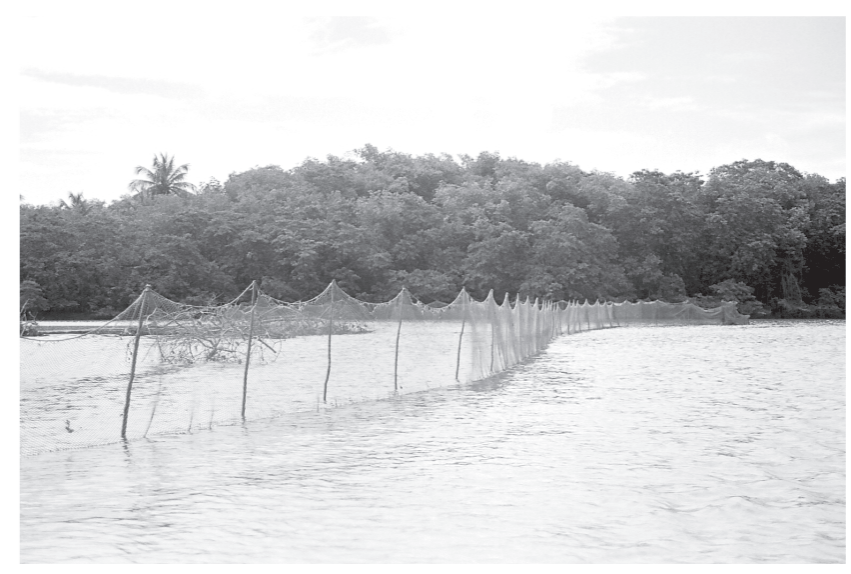

Figura 10 - Rede tainheira - pesca artesanal no canal do rio Parapuca - Boca do Arrombado. 


\section{Conclusões}

Considerando a análise referida a área de estudo se encontra exposta à ação dos processos naturais - costeiros e fluviais - e intervenções antrópicas. Assim, apresenta áreas sujeitas a elevada instabilidade, principalmente por conta do uso e/ou interação dos processos derivados de fatores naturais.

Embora as características das condições da dinâmica atmosférica local sejam atualmente determinantes na intensidade da ação dos processos morfogenéticos, a dinâmica do sistema ambiental local é reflexo da interação de condicionantes naturais e antrópicos presentes no âmbito da totalidade da bacia do rio São Francisco.

A regularização das vazões, a partir da construção das barragens, reduziu as possibilidades de ocorrência das enchentes que antes permitiam a inundação natural das várzeas e a distribuição dos nutrientes para a manutenção das lagoas onde a população local costumava, respectivamente, ocupar com cultivos e obter o pescado. Assim, esta situação tem gerado problemas de ordem econômica e social, com a necessidade de implantação de projetos sociais para suprir as carências da população.

Esta regularização das vazões tem contribuído para reduzir a quantidade de sedimentos à jusante. A redução na oferta tem propiciado a ação mais intensa dos processos costeiros na área estuarina, sendo possível observar alterações morfológicas na margem direita da foz do rio São Francisco, município de Brejo Grande, e no litoral adjacente.

Faz-se necessário, portanto buscar alternativas para conduzir as questões ambientais integrando os agentes sociais, o Poder Público e os estudiosos do meio ambiente como forma de buscar soluções para controlar ou minorar os problemas.

\section{Agradecimentos}

Os autores são gratos ao mestrando de Geografia da UFBA, Joseval dos Santos Palma, pela colaboração na organização dos mapas. Um agradecimento especial ao Prof. Dr. Pascal Jean Michel Motti por ter possibilitado, com suas contribuições e reflexões geomorfológicas, a realização desta análise geoambiental com base numa metodologia integradora dos pressupostos geossistêmicos e ecodinâmicos.

\section{Referências bibliográficas}

Almeida, J.A.P. de \& Gomes, L.J. (2006) Dinâmica da paisagem na foz do rio São Francisco a partir de imagens Landsat e CBERS. In: Simpósio Regional de Geoprocessamento e Sensoriamento Remoto, 3.,
Aracaju. Anais. Aracaju: EMBRAPA, CPATC. p. $1-5$.

Barbosa, L.M. (1997) Campos de dunas costeiras associados à desembocadura do Rio São Francisco (SE/AL): origem e controles ambientais. $214 \mathrm{f}$. Tese (Doutorado em Geologia) - Departamento de Geologia, Instituto de Geociências, UFBA, Salvador.

Barbosa, L.M. \& Dominguez, J.M.L. (2004) Coastal dune fields at the São Francisco river strandplain, northeastern Brazil: morphology and environmental controls. Earth Surface Processes and Landforms, 29: 443456.

Bertrand, G. (1971) Paisagem e geografia física global: esboço metodológico. Caderno de Ciências da Terra, n. $13,27 \mathrm{p}$.

Bittencourt, A.C.S.P.; Martin, L. \& Dominguez, J. M. L. (1983) Evolução paleogeográfica quaternária da costa do estado de Sergipe e costa sul do estado de Alagoas. Revista Brasileira de Geociências, São Paulo, 13 (2): 93-97.

Bittencourt, A.C.S.P.; Dominguez, J.M.L.; Fontes, L.C.S.; Sousa, D.L.; Silva, I.R. \& Silva, F.R. (2007) Wave refraction, river damming, and episodes of severe shoreline erosion: the São Francisco river mouth, northeastern Brazil. Journal of Coastal Research, 23 (4): 930-938.

Bomfim, L.F.C. (2002) Projeto Cadastro da infra-estrutura hídrica do Nordeste: estado de Sergipe. Diagnóstico do município de Brejo Grande. Aracaju: CPRM. 12 p.

Brasil. Ministério do Exército. Diretoria do Serviço Geográfico. (1971) Propriá: SC.24-Z-B-II. Brasília. 1 mapa. Escala 1:100.000.

Brasil. Ministério das Minas e Energia. Projeto Radambrasil. (1983) Folha SC.24/25 Aracaju/Recife: geologia, geomorfologia, pedologia, vegetação, uso potencial da terra. Rio de Janeiro, (Levantamento de Recursos Naturais), 851p.

Carvalho, M.E.S. \& Fontes, A.L. (2006) Estudo ambiental da zona costeira sergipana como subsídio ao ordenamento territorial. Revista Geonordeste, 2: $10-39$.

Dominguez, J.M.L.; Bittencourt, A.C.S.P; Martin, L. (1983) O papel da deriva litorânea de sedimentos arenosos na construção das planícies costeiras associadas às desembocaduras dos rios São Francisco (SEAL), Jequitinhonha (BA), Doce (ES) e Paraíba do 
Dinâmica geoambiental, processos morfodinâmicos e uso das terras...

Sul (RJ). Revista Brasileira de Geociências, 13 (2): $98-105$.

Fontes, L.C. da S. (Coord.) (2003) Projeto de gerenciamento integrado das atividades desenvolvidas em terra na Bacia do São Francisco. Subprojeto 2.4 Estudo do processo erosivo das margens do baixo São Francisco e seus efeitos na dinâmica de sedimentação do rio. Resumo executivo do relatório final. Brasília: Agência Nacional de Águas. $79 \mathrm{p}$.

Instituto Brasileiro de Geografia e Estatística - IBGE (1995) Estado de Sergipe: mapa de uso da terra [Rio de Janeiro]. 1 mapa, color. Escala 1:350.000.

Instituto Brasileiro de Geografia e Estatística - IBGE (2004) Resultados da Amostra do Censo Demográfico 2000 - Malha municipal digital do Brasil: situação em 2001. Rio de Janeiro: IBGE.

Medeiros, P.R.P. (Coord.) (2003) Projeto de gerenciamento integrado das atividades desenvolvidas em terra na Bacia do São Francisco. Subprojeto 1.1.B. Determinação da carga de nutrientes do rio São Francisco na região de sua foz. Resumo executivo do relatório final. Brasília: Agência Nacional de Águas. 57 p.

Motti, P. \& Motti, C. (1973) O estudo integrado do meio natural: o mapa dos geossistemas da área de Santa Quitéria (Ibitiara), Bahia. In: Congresso Brasileiro de Geologia, 27, Aracaju. Anais. Aracaju: SBG, p. 385392.

Santos, R.A. dos et al. (1998) Geologia e recursos minerais do estado de Sergipe: texto explicativo do mapa geológico do estado de Sergipe. Brasília: CPRM; Aracaju: CODISE, 107p. (Programa Levantamentos Geológicos Básicos do Brasil).
Secretaria de Estado do Planejamento de Sergipe - SEPLAN. (2007) Mapa territórios sergipanos. Aracaju: GIGEC/SUPES/SEPLAN. 1 mapa, color. Escala $1: 800.000$.

Secretaria de Estado do Planejamento e da Ciência e Tecnologia - SEPLANTEC. (2002) Atlas digital sobre recursos hídricos de Sergipe. PROJETO Cadastro da infraestrutura hídrica do Nordeste: Sergipe. Brasília: CPRM; Aracaju: SEPLANTEC/SE. $1 \mathrm{Cd}$.

Sergipe. (2003) Secretaria do Planejamento e da Ciência e Tecnologia. Base cartográfica dos municípios litorâneos de Sergipe. Aracaju. 1 ortofotocarta. Escala 1:10.000. 1 CD-ROM.

Silva, G. B. (2007) (Comp.) Mapa exploratório-reconhecimento de solos do estado de Sergipe. Salvador: IBGE. 1 mapa, color. Escala 1:500.000.

Superintendência do Desenvolvimento do Nordeste SUDENE. (1974a) Cabeço: SC.24-Z-B-VI. Aracaju. 1 mapa. Escala 1:100.000.

Superintendência do Desenvolvimento do Nordeste SUDENE. (1974b) Japaratuba: SC.24-Z-B-V. Aracaju, 1974. 1 mapa. Escala 1:100.000.

Superintendência do Desenvolvimento do Nordeste SUDENE. (1974c) Piaçabuçu: SC.24-Z-B-III. Aracaju, 1974. 1 mapa. Escala 1:100.000.

Tricart, J. (1977) Ecodinâmica. Rio de Janeiro: IBGE. 91 p. (Recursos naturais e meio ambiente, 1 ).

Universidade Federal de Sergipe - UFS. (1979) Atlas de Sergipe. Aracaju. 95 p. 
